\title{
Spontaneous intramural esophageal hematoma: Case report and review
}

\author{
Justin Cheung MD ${ }^{1}$, Nestor Müller MD PhD FRCPC ${ }^{2}$, Alan Weiss MD FRCPC ${ }^{1}$
}

\begin{abstract}
J Cheung, N Müller, A Weiss. Spontaneous intramural esophageal hematoma: Case report and review. Can J Gastroenterol 2006;20(4):285-286.

Intramural esophageal hematoma is a rare form of esophageal injury. The presenting symptoms are nonspecific. Esophagogastroscopy and computed tomography scan are usually needed to establish the diagnosis of intramural esophageal hematoma. Presented here is a patient with spontaneous intramural esophageal hematoma who was successfully treated with conservative measures.
\end{abstract}

\section{Un hématome intramural spontané de l'œsophage : Rapport de cas et analyse}

\begin{abstract}
L'hématome intramural de l'œsophage est une forme rare de lésion œsophagienne. Les manifestations initiales ne sont pas spécifiques. L'œsogastroscopie et la tomodensitométrie sont généralement nécessaires pour poser le diagnostic. Est présenté le cas d'un patient atteint d'un hématome intramural de l'œsophage chez qui un traitement classique a réussi.
\end{abstract}

Key Words: Dissection; Esophageal; Hematoma; Hemorrhage; Intramural

C sophageal wall injuries may present as a tear (MalloryEWeiss tear), an esophageal rupture (Boerhaave syndrome) and, more rarely, as an intramural hematoma. Intramural esophageal hematomas (IEHs) may present spontaneously or after trauma, such as from instrumentation (1-4). IEHs may develop following an episode of vomiting or may occur spontaneously secondary to bleeding diatheses. The usual presentation is sudden onset of retrosternal chest pain (2,5-7). Thus, early diagnosis may be difficult because of the nonspecific nature of the retrosternal chest pain. Described here is a patient with IEH, including serial endoscopic and radiological findings.

\section{CASE PRESENTATION}

A 66-year-old woman with a history of hypertension presented with an acute onset of chest pain, associated with an episode of retching and then vomiting of normal stomach contents. This was followed by two episodes of hematemesis. She had no prior history of gastrointestinal, cardiac, pulmonary or bleeding disorders. The patient's medications included acetylsalicylic acid (81 mg once daily) and antihypertensives. On examination, she was hemodynamically stable. Cardiac, respiratory and abdominal examinations were normal. The initial hemoglobin concentration was $131 \mathrm{~g} / \mathrm{L}$ and, 3 h later, was $125 \mathrm{~g} / \mathrm{L}$. Platelet count, international normalized ratio, partial thromboplastin time, liver enzymes, troponin and electrocardiogram were normal. A chest $\mathrm{x}$-ray was normal. The patient underwent upper gastrointestinal endoscopy, which revealed large amounts of clotted esophageal blood. After irrigation of the esophageal lumen with water, extensive esophagitis with mucosal friability and two bluish columns with intraluminal bulging running from the proximal esophagus to the

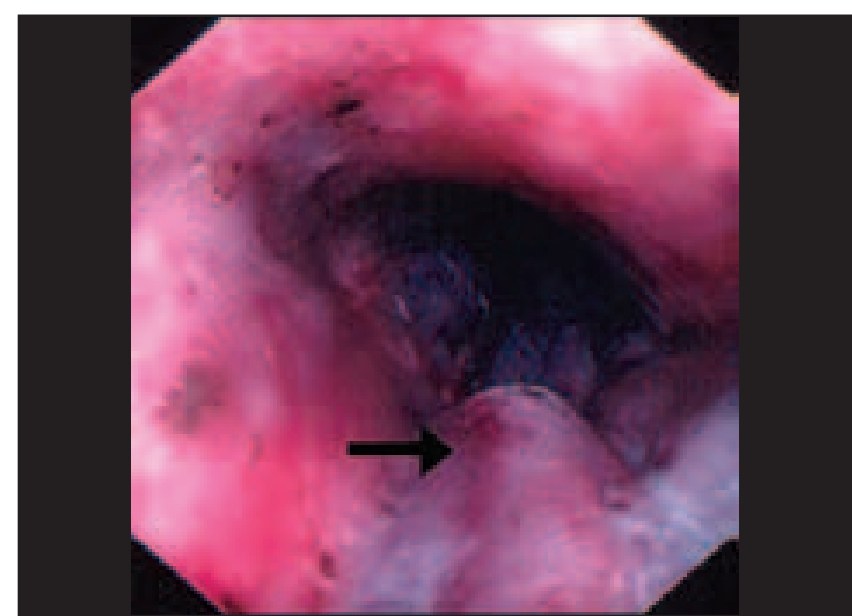

Figure 1) Initial upper endoscopy showing inflammation of the mucosa and the intramural esophageal hematoma with a bluish-tinged longitudinal column (arrow)

gastroesophageal junction were observed (Figure 1). A biopsy was not performed because of mucosal friability. The differential diagnosis at this point included esophageal IEH, but also varices, tumour and extrinsic mass compression.

An abdominal ultrasound was normal. A chest computed tomography (CT) scan showed that the esophagus was dilated and the lumen was almost completely filled with a homogeneous tissue density extending from the level of the carina to the gastroesophageal junction (Figure 2). The findings were consistent with an IEH. There was no evidence of perforation on CT or with a gastrograffin swallowing study. Endoscopy was repeated two days later, which showed no

${ }^{1}$ Department of Medicine, Division of Gastroenterology; ${ }^{2}$ Department of Radiology, Vancouver General Hospital, University of British Columbia, Vancouver, British Columbia

Correspondence: Dr Alan Weiss, 903 - 750 West Broadway, Vancouver, British Columbia V5Z 1H8. Telephone 604-879-3992,

fax604-879-3912, e-mail aaweiss@telus.net

Received for publication July 30, 2005. Accepted August 31, 2005 


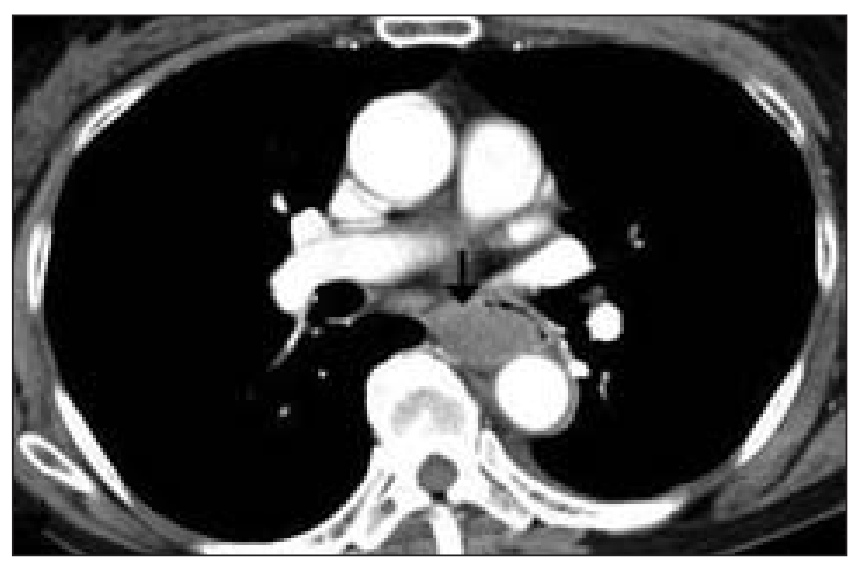

Figure 2) Contrast computed tomography scan demonstrating a large intramural esophageal hematoma (arrow) with luminal compression and a thin crescent of intraluminal air between the hematoma and the esophageal wall

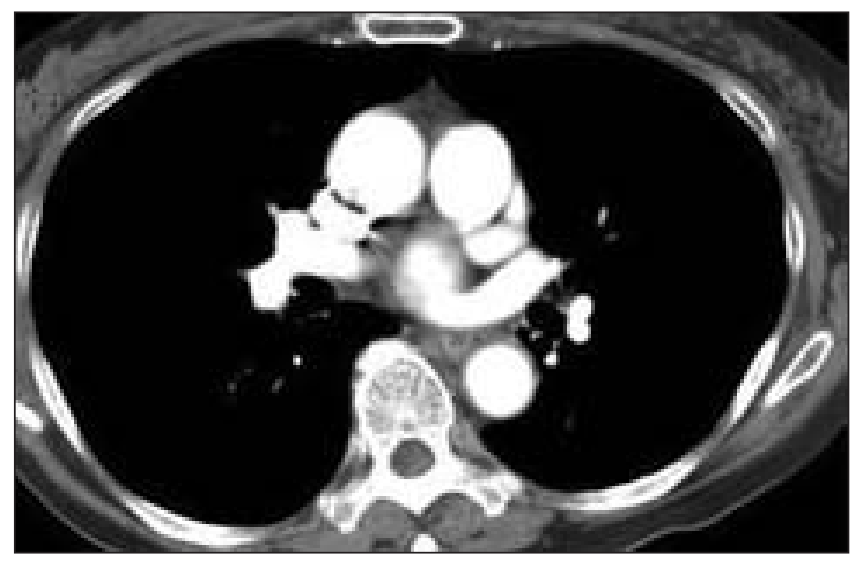

Figure 3) Contrast computed tomography scan two weeks later, demonstrating complete resolution of the intramural esophageal hematoma

change. The patient was treated conservatively with clear fluids, a proton pump inhibitor and discontinuation of acetylsalicylic acid. Four days later, she was asymptomatic, tolerating a full diet and discharged with a proton pump inhibitor. A repeat CT scan 14 days later revealed resolution of the esophageal hematoma (Figure 3). Forty-one days after presentation, a repeat endoscopy showed a normal esophagus (Figure 4).

\section{DISCUSSION}

IEHs are an uncommon form of an esophageal injury. IEHs have been described in the literature as esophageal apoplexy, intramural hemorrhage and intramural dissection. It may occur following an esophageal dilation procedure $(4,5)$. However, it can also present without any preceding event, and thus, the term spontaneous IEH (SIEH) may be used (1-3,5). Female sex and coagulopathy have been described as risk factors for SIEH (6-8). The most common presenting symptoms are chest pain and/or hematemesis. The triad of chest pain, dysphagia and hematemesis is present in 35\% of individuals. Other symptoms may include epigastric pain and odynophagia. Since the presenting symptoms are nonspecific and SIEH is rare, other cardiovascular and gastrointestinal conditions are usually considered before the diagnosis is established $(3,5,9)$. In addition, endoscopic findings of a longitudinal vascular lesion or

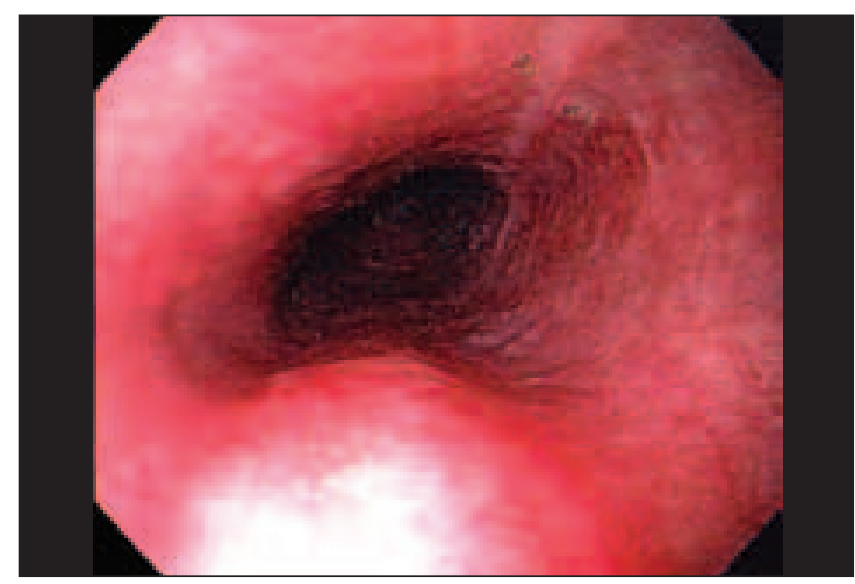

Figure 4) Upper endoscopy six weeks postevent, revealing complete resolution of the esophageal intramural hematoma

a mass lesion with luminal compression may suggest the presence of esophageal varices and malignancies (10). The classic finding on a gastrograffin swallow study is the 'double barrel' sign, but more frequently, an intraluminal filling defect is demonstrated. A CT scan may detect an intraluminal or intramural soft tissue density. The examination of choice is upper gastrointestinal endoscopy, which often reveals a friable mucosa with a bluish longitudinal hematoma, with or without evidence of mucosal breach. Endoscopic ultrasound may also be helpful in establishing the diagnosis.

SIEHs generally have a benign course and resolve within three weeks of conservative management (11). The patient described in this report was managed conservatively. By two weeks, there was no further esophageal hematoma on CT scan. By six weeks, there was complete mucosal resolution on endoscopy.

\section{REFERENCES}

1. Geller A, Gostout CJ. Esophagogastric hematoma mimicking a malignant neoplasm: Clinical manifestations, diagnosis, and treatment. Mayo Clin Proc 1998;73:342-5.

2. Gluck M, Jiranek GC, Low DE, Kozarek RA. Spontaneous intramural rupture of the esophagus: Clinical presentation and endoscopic findings. Gastrointest Endosc 2002;56:134-6.

3. Spanier BW, Bruno MJ, Meijer JL. Spontaneous esophageal hematoma. Gastrointest Endosc 2003;58:755-6.

4. Younes Z, Johnson DA. The spectrum of spontaneous and iatrogenic esophageal injury: Perforations, Mallory-Weiss tears, and hematomas. J Clin Gastroenterol 1999;29:306-17.

5. Lu MS, Liu YH, Liu HP, Wu YC, Chu Y, Chu JJ. Spontaneous intramural esophageal hematoma. Ann Thorac Surg 2004;78:343-5.

6. Yamashita K, Okuda H, Fukushima MD, Arimura Y, Endo T, Imai K. A case of intramural esophageal hematoma: Complication of anticoagulation with heparin. Gastrointest Endosc 2000;52:559-61.

7. Ashman FC, Hill MC, Saba GP, Diaconis JN. Esophageal hematoma associated with thrombocytopenia. Gastrointest Radiol 1978;3:115-8.

8. Folan RD, Smith RE, Head JM. Esophageal hematoma and tear requiring emergency surgical intervention. A case report and literature review. Dig Dis Sci 1992;37:1918-21.

9. Enns R, Brown JA, Halparin L. Intramural esophageal hematoma: A diagnostic dilemma. Gastrointest Endosc 2000;51:757-9.

10. Meininger M, Bains M, Yusuf S, Gerdes H. Esophageal intramural hematoma: A painful condition that may mimic an esophageal mass. Gastrointest Endosc 2002;56:767-70.

11. Jung KW, Lee OJ. Extensive spontaneous submucosal dissection of the esophagus: Long-term sequential endoscopic observation and treatment. Gastrointest Endosc 2002;55:262-5. 


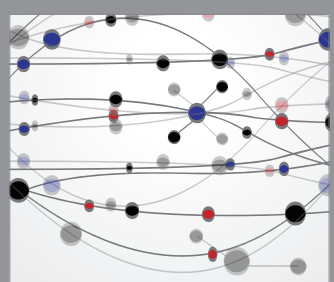

The Scientific World Journal
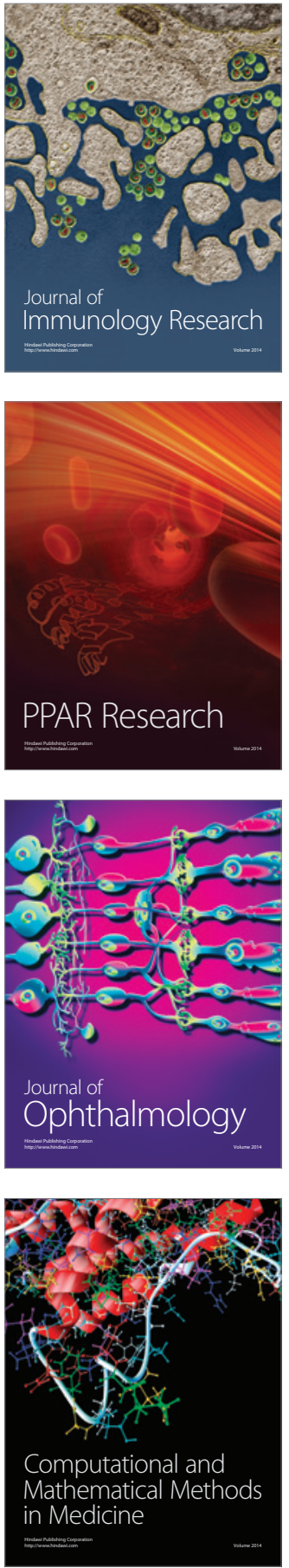

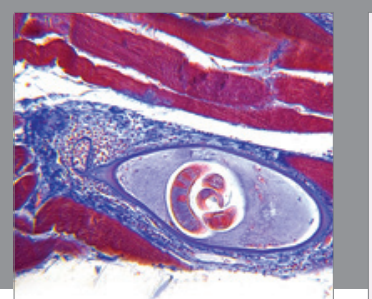

Gastroenterology Research and Practice

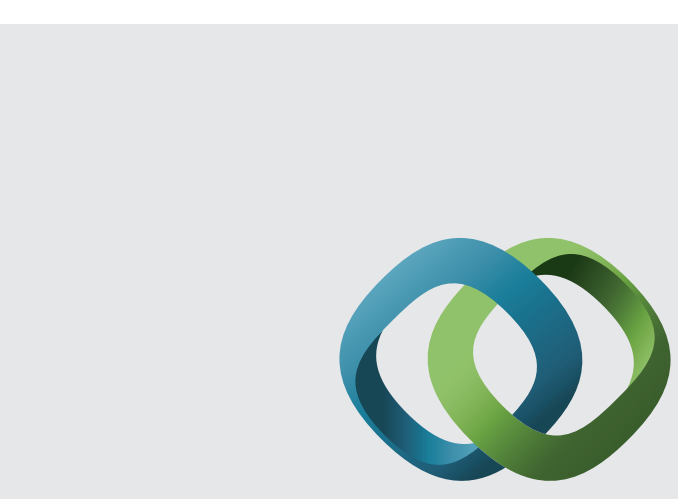

\section{Hindawi}

Submit your manuscripts at

http://www.hindawi.com
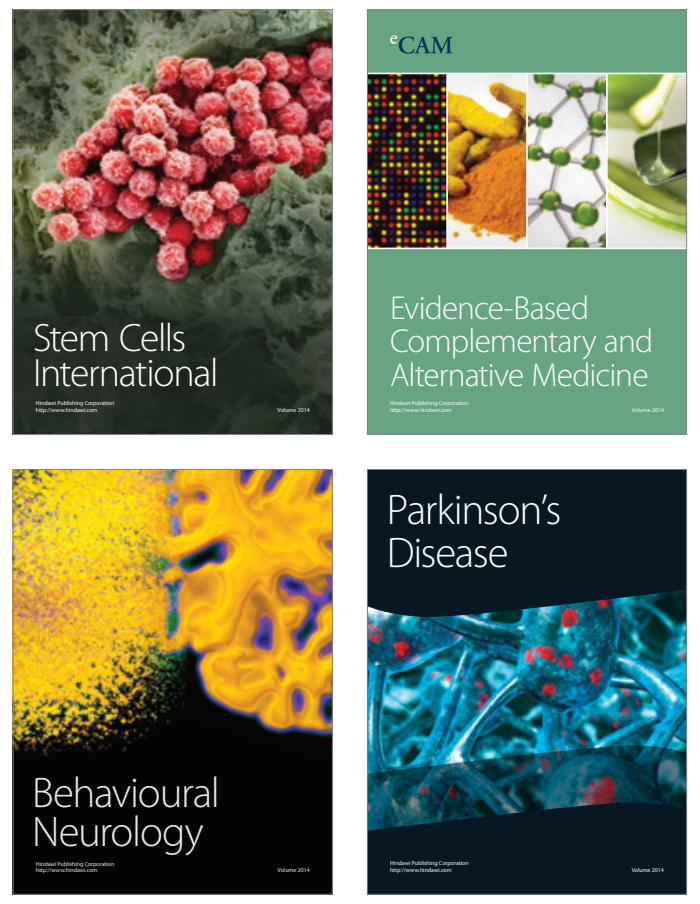
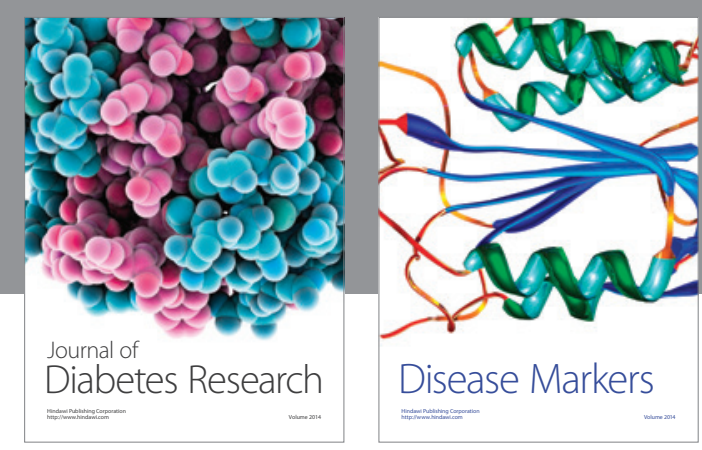

Disease Markers
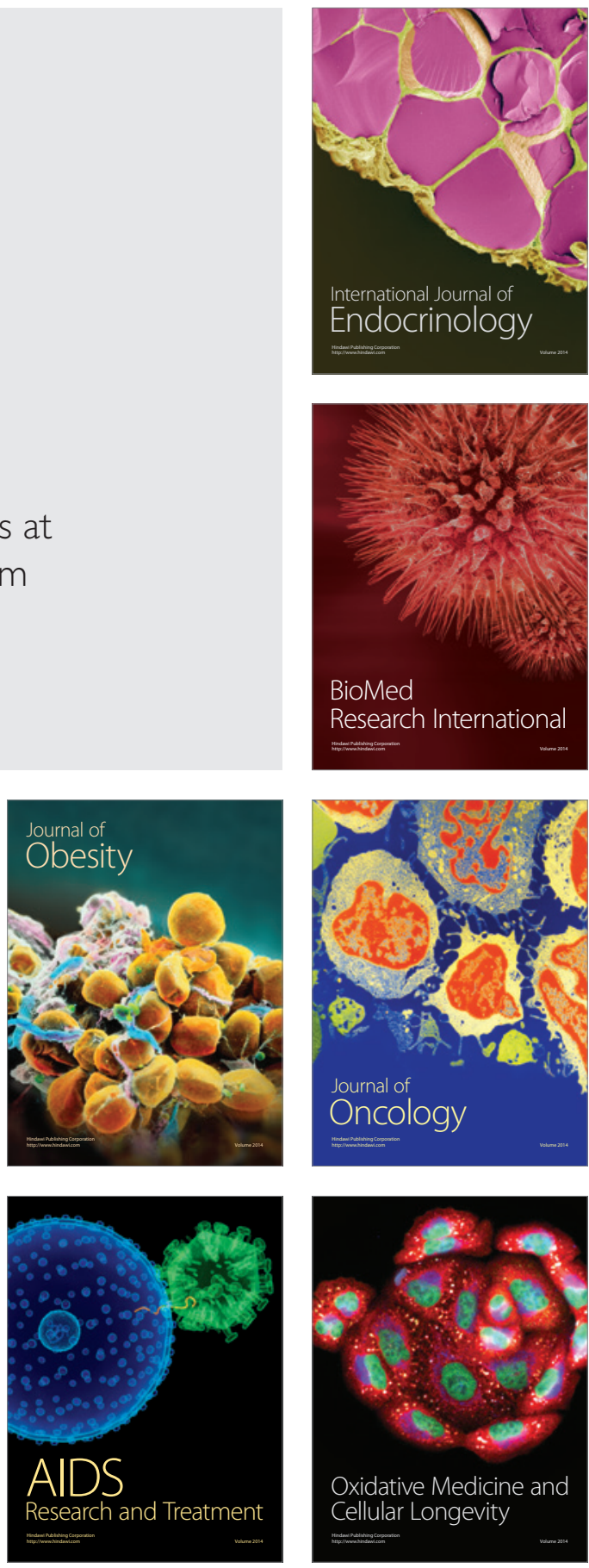